\title{
DETERMINING INFLUENCE OF
} ALLOYING ELEMENTS ON PROPERTIES OF ALLOYS BY ROBUST EXPERIMENT

\author{
Nikolay Tontchev \\ Transport University of Sofia, Bulgaria \\ Yordan Kalev \\ Transport University of Sofia, Bulgaria
}

\section{(C) MESTE NGO}

Category: Research article

\begin{abstract}
The paper presents an approach to determine the influence of alloying elements on the properties of iron-based alloys by a robust numerical experiment. The study is based on a database of 90 alloys with relationship between the chemical composition and mechanical and plastic properties. The limit of yield strength $(R e)$ and elongation $(A)$ are assumed as optimizing parameters. The properties of the alloys used in the database are under heat-treated condition after low temperature hardening and tempering applied. In terms of the mission of any performance steels were identified nonlinear regression relationships. As a result, the proposed procedure shows how to specify the amount of alloying elements on iron alloys based on the Taguchi method. The originality of the solution lies in application of the Taguchi method for simultaneous multiple criteria within a task.
\end{abstract}

\section{Keywwords:}

ferrous alloys, robust numerical experiment, Taguchi method, modelling and optimization properties

\section{INTRODUCTION}

For the past few decades the attention of many engineers and statisticians in the world has been drawn to the so-called Taguchi method. A lot of successful applications of this method have been reported in designing quality products using

The address of the corresponding author: Nikolay Tontchev

䒠三” tontchev@vtu.bg modern techniques such as neural networks and genetic algorithms. A number of examples in the field of metallurgy and processing of blanks are presented in the results from the Taguchi-based research by Adem, Turgay, \& Gurcan (2012), Bajic, Jozic, \& Podrug (2010), and Gaitonde, Karmik, \& Davim (2009) for processing metal surfaces and for machining of holes. Machining parameters are optimized to obtain higher quality surfaces. The same approach is used from Kochure \& Nandurkar (2012) for selection of induction 
hardening parameters. The Taguchi approach is applied from Naveen, Maheshwari, Sharma, \& Anil (2008) for powder metallurgical production of electrodes and their behavior is compared to the behavior of a copper one. The maximal strength of castings from aluminium for the Taguchi-based approach is realized by Oji, Pamtoks, Idusuyi, \& Aliu (2012) and Ramesh \& Suresh (2012) the same approach is examined to explore the wear of friction surfaces; an unified model of the process is elaborated.

The core of Taguchi approach consists of the method for reducing the influence of factors called noise (disturbing) that impair the quality parameters of the product/process. It is where the radical difference from the traditional technique of quality, which provides identification of existing sources and conduction of measurements that are often costly due to their control. The parametric design of Taguchi ensures non-sensitivity to (interference) noise along the way to the proper selection of certain parameters called controllable factors.

In engineering practice, when the variance of the quality index is too large, it frequently involves narrowing of the tolerance ranges of the parameter examined. However, to narrow the tolerance intervals means to buy raw materials of higher quality, which are more expensive.

Therefore, robust engineering design provides high quality with low product. It also shows that quality products can be produced even if the raw materials are not of the highest quality.

The features of processes and products quality usually depend on many parameters. It is why that more sophisticated methods are needed to find such parameters of the product that make it insensitive to interference. Experiments are conducted where both the product parameters and noise conditions are modified. The goal of these experiments is to see how the joint effects of the product parameters and noise factors influence on the quality characteristics. (Kachar, Off line quality control parameters desing and Taguchi method, 1985)

The robust design is a step forward in comparison to the traditional methods of experiment planning and analysis where only the dependence of the quality index on the factors is studied. With robust design its dispersion is examined as well. (Kachar, 1986)

Taguchi uses plans called orthogonal arrays by the scheme shown in Fig.1.

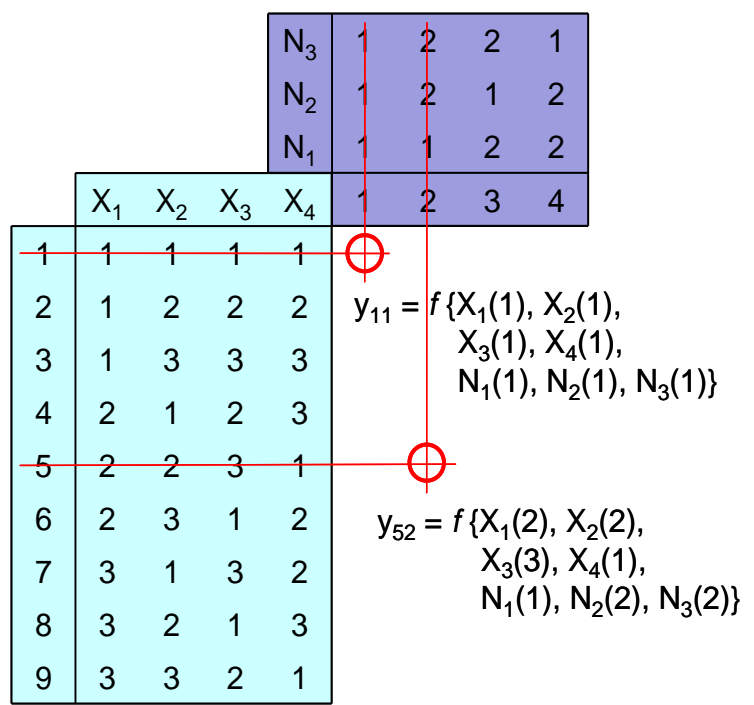

\section{Fig. 1. Orthogonal plans with four design parameters $X_{1}-X_{4}$ and three noise factors $N_{1}-N_{3}$.}

The problem is that in this case the experimenter has to preliminarily know which interactions are significant. Usually there is no such information.

Performing experiments according to the parameter plan in Fig.1, it is obtained that $\mathrm{N}=$ $\mathrm{N}_{9} \mathrm{~N}_{4}$ are the values of quality characteristics suitable for decision making. Taguchi uses the ratio $\frac{\text { signal }}{\text { noise }}\left(\frac{S}{N}\right)$ as a measure for statistics.

The effects of the factors are determined for each line as to minimize the performance characteristics the formula used is:

$$
\frac{S}{N}=-10 \log \left(\frac{1}{n} \sum_{j=1}^{n} y_{i j}^{2}\right)
$$

and for maximizing

$$
\frac{S}{N}=-10 \log \left(\frac{1}{n} \sum_{j=1}^{n} \frac{1}{y_{i j}^{2}}\right) \text {. }
$$

Two types of models describing the behavior of the quality characteristics can be created:

- model of the average values of quality index, - model of dispersion of the quality index. 
With these models available, robust design is reduced to an optimization problem. One of its possible formulations is the following: to select values of these product parameters to minimize the disperse of quality index provided that its average value is equal to the target value $y=$ Nom.

The research from refference shows the broad spectrum of problems in which Taguchi method is applied

The aim of this study is to present an approach to determine the influence of alloying elements on the properties of ferrous alloys with multi-criteria robust numerical experiment.

The wish is to achieve results that are better than the source used to obtain the mathematical model

\section{ESSENCE OF THE NUMERICAL PROCEDURE}

A database of 90 alloys found at [http://www.splav.kharkov.com/choose_type.php] is used as a basis of the study. The database cited contains the relationship between the chemical composition and mechanical properties of alloys involved. It contains data on the quantities of carbon $\mathrm{C}$, silicon $\mathrm{Si}$, manganese $\mathrm{Mn}$, nickel $\mathrm{Ni}$, chromium $\mathrm{Cr}$, molybdenum $\mathrm{Mo}$, sulfur $\mathrm{S}$ and phosphorus $\mathrm{P}$. These are the input variables of the model. For mathematical models based on the chemical composition it is reported by Efimychev, Mikhailov, Svyatkina \& Prokhorov (1976) and Rozhkov, Vlasov \& Mulk (1990).

Table 1. Minimum and maximum values of alloying components

\begin{tabular}{|c|c|l|l|}
$\begin{array}{c}\text { Input } \\
\text { parameter }\end{array}$ & $\begin{array}{c}\text { Chemical } \\
\text { symbol }\end{array}$ & $\begin{array}{c}\text { min } \\
{[\%]}\end{array}$ & $\begin{array}{c}\max \\
{[\%]}\end{array}$ \\
\hline $\mathrm{x}_{1}$ & $\mathrm{C}$ & 0.12 & 0.52 \\
\hline $\mathrm{x}_{2}$ & $\mathrm{Si}$ & 0.27 & 1.4 \\
\hline $\mathrm{x}_{3}$ & $\mathrm{Mn}$ & 0.35 & 1.75 \\
\hline $\mathrm{X}_{4}$ & $\mathrm{Ni}$ & 0 & 4.22 \\
\hline $\mathrm{x}_{5}$ & $\mathrm{~S} / \mathrm{P}$ & 0.025 & 0.035 \\
\hline $\mathrm{x}_{6}$ & $\mathrm{Cr}$ & 0.15 & 2.50 \\
\hline $\mathrm{x}_{7}$ & $\mathrm{Mo}$ & 0 & 1.5 \\
\hline $\mathrm{x}_{8}$ & $\mathrm{~V}$ & 0 & 0.45 \\
\hline
\end{tabular}

The properties of the alloys in this database are under heat-treated condition after applying low temperature hardening and tempering.

The optimizing parameters are: the yield strength $\mathrm{Re}$ and elongation $\mathrm{A}$. The ranges of change of the used alloying elements of ferrous alloys are listed in Table 1.

Table 2. Coefficients of regression models of the target parameters under examination

\begin{tabular}{|c|c|c|c|}
\hline No & $\begin{array}{c}\text { Coeffi- } \\
\text { cient }\end{array}$ & $\begin{array}{c}\mathrm{Re} \\
{[\mathrm{MPa}]}\end{array}$ & $\begin{array}{c}\mathrm{A} \\
{[\%]}\end{array}$ \\
\hline 1 & $\mathrm{C}_{0}$ & 2114.1150 & 46.556931 \\
\hline 2 & $\mathrm{X}_{1}$ & 7756.8407 & -.5162068 \\
\hline 3 & $\mathrm{X}_{2}$ & 7199.1880 & -39.72085 \\
\hline 4 & $\mathrm{X}_{3}$ & -7695.0560 & -11.96989 \\
\hline 5 & $\mathrm{X}_{4}$ & -208.3606 & -6.194367 \\
\hline 6 & $\mathrm{X}_{5}$ & -206849.10 & 608.78794 \\
\hline 7 & $\mathrm{X}_{6}$ & 3214.6636 & -44.13384 \\
\hline 8 & $\mathrm{X}_{7}$ & -25808.88 & 296.07430 \\
\hline 9 & $\mathrm{X}_{8}$ & 88806.163 & -1272.128 \\
\hline 10 & $\mathrm{X}_{1} \mathrm{X}_{2}$ & -386.6554 & -17.34393 \\
\hline 11 & $\mathrm{X}_{1} \mathrm{X}_{3}$ & -1070.550 & 4.4991108 \\
\hline 13 & $\mathrm{X}_{1} \mathrm{X}_{5}$ & -136396.0 & -479.9262 \\
\hline 14 & $\mathrm{X}_{1} \mathrm{X}_{6}$ & -937.1690 & 10.247712 \\
\hline 15 & $\mathrm{X}_{1} \mathrm{X}_{7}$ & -4306.703 & 56.210086 \\
\hline 16 & $\mathrm{X}_{1} \mathrm{X}_{8}$ & 28210.222 & -234.0791 \\
\hline 17 & $\mathrm{X}_{2} \mathrm{X}_{3}$ & -2441.408 & 8.1761576 \\
\hline 18 & $\mathrm{X}_{2} \mathrm{X}_{4}$ & 1139.5872 & 9.5115582 \\
\hline 19 & $\mathrm{X}_{2} \mathrm{X}_{5}$ & -136064.2 & 630.64368 \\
\hline 20 & $\mathrm{X}_{2} \mathrm{X}_{6}$ & -3798.235 & 24.332090 \\
\hline 21 & $\mathrm{X}_{2} \mathrm{X}_{7}$ & 90881.356 & -1331.408 \\
\hline 22 & $\mathrm{X}_{2} \mathrm{X}_{8}$ & -385523.8 & 5120.2990 \\
\hline 23 & $\mathrm{X}_{3} \mathrm{X}_{4}$ & 461.26479 & -3.247065 \\
\hline 24 & $\mathrm{X}_{3} \mathrm{X}_{5}$ & 235316.49 & -444.5946 \\
\hline 25 & $\mathrm{X}_{3} \mathrm{X}_{6}$ & -45.97452 & 11.423925 \\
\hline 26 & $\mathrm{X}_{3} \mathrm{X}_{7}$ & 3249.6850 & -13.73530 \\
\hline 27 & $\mathrm{X}_{3} \mathrm{X}_{8}$ & -4913.023 & 110.24208 \\
\hline 28 & $\mathrm{X}_{4} \mathrm{X}_{5}$ & -5816.934 & 59.110091 \\
\hline 30 & $\mathrm{X}_{4} \mathrm{X}_{6}$ & -159.9173 & 4.3070441 \\
\hline $\mathrm{X}_{4} \mathrm{X}_{7}$ & -6.156909 & -2.088778 \\
\hline & $\mathrm{X}_{5} \mathrm{X}_{6}$ & -105.0768 & -73706332 \\
\hline & & -27149.24 & 187.81631 \\
\hline
\end{tabular}


Tontchev N. The influence of elements on alloys properties

MEST Journal Vol. 1 No. 2 pp. 31 - 39

\begin{tabular}{|c|c|c|c|}
\hline No & $\begin{array}{c}\text { Coeffi- } \\
\text { cient }\end{array}$ & $\begin{array}{c}\mathrm{Re} \\
{[\mathrm{MPa}]}\end{array}$ & $\begin{array}{c}\mathrm{A} \\
{[\%]}\end{array}$ \\
\hline 33 & $\mathrm{X}_{5} \mathrm{X}_{7}$ & 41678.774 & 884.54626 \\
\hline 34 & $\mathrm{X}_{5} \mathrm{X}_{8}$ & 300515.42 & -2272.635 \\
\hline 35 & $\mathrm{X}_{6} \mathrm{X}_{7}$ & -1228.339 & 32.838349 \\
\hline 36 & $\mathrm{X}_{6} \mathrm{X}_{8}$ & 1056.322 & 2.7722696 \\
\hline 37 & $\mathrm{X}_{7} \mathrm{X}_{8}$ & 3239.252 & 51.757562 \\
\hline 38 & $\mathrm{X}_{1}^{2}$ & -992.3896 & 2.2481142 \\
\hline 39 & $\mathrm{X}_{2}^{2}$ & 2493.712 & -4.790038 \\
\hline 40 & $\mathrm{X}_{3}^{2}$ & 184.2402 & 6.8702503 \\
\hline 41 & $\mathrm{X}_{4}^{2}$ & 34.06016 & .22590263 \\
\hline 42 & $\mathrm{X}_{5}^{2}$ & 3139839. & -13811.99 \\
\hline 43 & $\mathrm{X}_{6}^{2}$ & -242.5842 & 3.7158944 \\
\hline 44 & $\mathrm{X}_{7}^{2}$ & 891.8651 & -9.448061 \\
\hline 45 & $\mathrm{X}_{8}^{2}$ & -4756.548 & -356.8126 \\
\hline & $\mathbf{R}$ & 0.8755 & 0.8632 \\
\hline
\end{tabular}

According to Vuchkov and Stoyanov (1980), K if $F>F(\alpha, v 1, v 2)$ then the coefficient of multiple correlation $\mathrm{R}$ is significant and the model can be used for prediction.

In regard to the problem examined, for each of the mechanical properties of steels under examination nonlinear regression dependencies of the kind have been identified:

$f_{i}(x)=b_{00}^{i}+\sum_{j=1}^{8} b_{j 0}^{i} x_{j}+\sum_{j=1 l=j+1}^{8} \sum_{j l}^{8} b_{j} x_{l}+\sum_{j=1}^{8} b_{j j}^{i} x_{j}^{2}$

Here $b_{i j}$ are the parameters of the regression model.

An experiment is carried out by the methodology of Taguchi modeled on orthogonal matrices developed by it. The experiment can be implemented in two ways:

- a real experiment thanks to which results for processing are obtained;

- numerical experiment with availability of adequate regression models.

The presence of coefficients of adequate models described in Table 2 makes it possible to carry out numerical simulation by the scheme presented in Fig. 1. The orthogonal matrix I with 27 rows and 13 columns given in Table $3(27,13)$ is chosen as a noise matrix. The matrix is derived with factors at three levels.

Specifically for the data of the experiment, eight pillars are used as the regression models are obtained based on eight variables.

In the matrix $X_{1}$ corresponds to carbon, $X_{2}$ corresponds to silicon, $X_{3}$ corresponds to manganese, $X_{4}$ corresponds to nickel, $X_{5}$ corresponds to sulfur and phosphorus, $X_{6}$ corresponds to chromium, $X_{7}$ corresponds to molybdenum and $\mathrm{X}_{8}$ corresponds to vanadium.

The methodology proposed will be used to analyze yield strength $\mathrm{Re}$ and elongation $\mathrm{A}$. To build these two target functions, 90 measurements that form the data matrix $\mathrm{A}(90,8$ +1 ) have been used. Here the added column "1" is for the output target function Re or A, stored compactly in the matrix.

To optimize the computing process, the scheme in Fig. 2 is selected, which having been processed for the particular case takes the following kind.

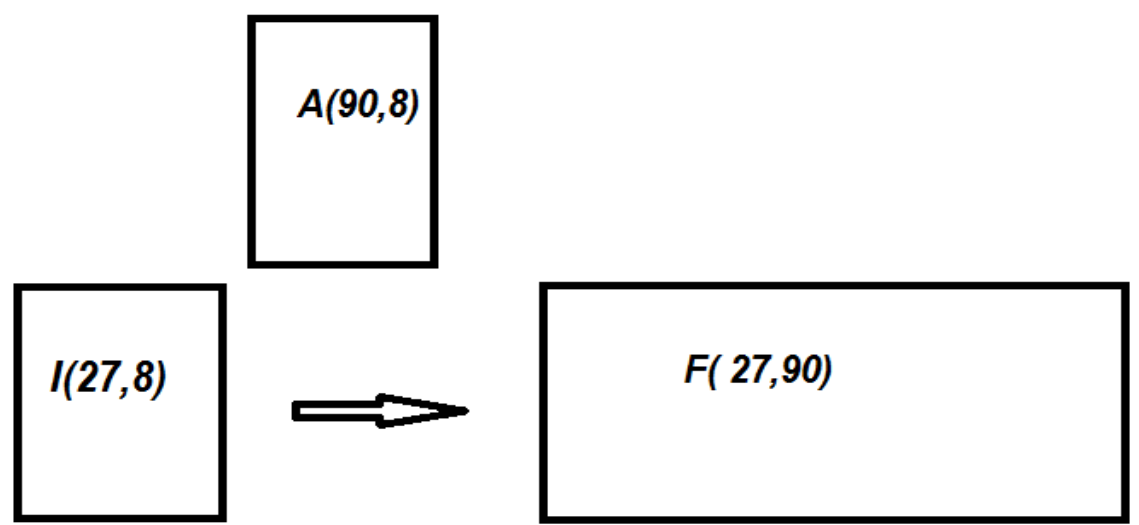

Fig. 2 Organizing experiments with parametric planning with matrices I, A and F 
In numerical experiments that use models based on the chemical composition the noise can be expressed only in the change of the respective components. It is assumed to express noise $\Delta$ in the following way $\Delta_{i}=\frac{\bar{x}_{i}}{k} \quad$ where further calculations are made for $k$ equal to 100 and 70 .

Here $\bar{x}_{i}$ is the mean value of relevant variable "i".

For level "1" of I $(27,8)$ noise is subtracted from relevant $x_{i}$ taking the value of $x_{i}-\Delta_{i}$. With level "2" no correction is applied, the value of $x_{i}$ is preserved. With level " 3 " noise is added to relevant $x_{i}$ taking the value of $x_{i}+\Delta_{i}$.

Thus, noise is expressed in the change of chemical composition. The calculation process is organized as follows:

A row of matrix I $(27,8)$ is taken (for example, row 1 - I $(1,8))$. In this row for each $x_{i}$ level " $1 "$ is assigned, i.e. noise will be taken out from each value $x_{i}$. Using the rule expresed in this way, noise is generally formed in the first row of matrix A (90.8), calculated by the mathematical model and the result forms $F(1,1)$ of matrix $F(27,90)$. The same rule is applies to the next rows of the matrix A $(90,8)$.

It is continued with the next row of matrix I $(27,8)$ performing the following sequence. Each row of matrix I $(27,8)$ forms a relevant row of matrix $F(27,90)$.
If we take the first column of matrix I $(27,8)$ relevant to $X_{1}$, it is seen that the first nine rows correspond to level "1" of noise, the second nine lines correspond to level "2" and the third nine rows correspond to level " 3 " of noise. This makes possible to use the values of the first nine rows of matrix $F(27,90)$ to calculate level "1", to use the second nine rows to calculate level of "2" and the third nine rows for calculation at level " 3 " for $X_{1}$. For other columns from 2 to 8 it is necessary to sort in ascending order. After sorting the column obtains the kind of the first column. If changes are made with sorting, they are reflected also in matrix $F(27,90)$. After sorting of the respective variable, calculations for different levels can be made.

In numerical experiments that use models based on the chemical composition the noise can be expressed only in the change of the respective components. It is assumed to express noise $\Delta$ in the following way $\Delta_{i}=\frac{\bar{x}_{i}}{k} \quad$ where further calculations are made for $k$ equal to 100 and 70 .

Here $\bar{x}_{i}$ is the mean value of relevant variable "i".

For level "1" of I $(27,8)$ noise is subtracted from relevant $x_{i}$ taking the value of $x_{i}-\Delta_{i}$. With level "2" no correction is applied, the value of $x_{i}$ is preserved. With level " 3 " noise is added to relevant $x_{i}$ taking the value of $x_{i}+\Delta_{i}$.

Table 3. $L_{27}-A 3^{13-10}$ Fractional Factorial Design Thirteen Factors at Three Levels (27 Runs)

\begin{tabular}{|c|c|c|c|c|c|c|c|c|c|c|c|c|c|}
\hline Run & $\mathrm{X} 1$ & $\mathrm{X} 2$ & $\mathrm{X} 3$ & $\mathrm{X} 4$ & $\mathrm{X} 5$ & $\mathrm{X} 6$ & $\mathrm{X} 7$ & $\mathrm{X} 8$ & $\mathrm{X} 9$ & $\mathrm{X} 10$ & $\mathrm{X} 11$ & $\mathrm{X} 12$ & $\mathrm{X} 13$ \\
\hline 1 & 1 & 1 & 1 & 1 & 1 & 1 & 1 & 1 & 1 & 1 & 1 & 1 & 1 \\
\hline 2 & 1 & 1 & 1 & 1 & 2 & 2 & 2 & 2 & 2 & 2 & 2 & 2 & 2 \\
\hline 3 & 1 & 1 & 1 & 1 & 3 & 3 & 3 & 3 & 3 & 3 & 3 & 3 & 3 \\
\hline 4 & 1 & 2 & 2 & 2 & 1 & 1 & 1 & 2 & 2 & 2 & 3 & 3 & 3 \\
\hline 5 & 1 & 2 & 2 & 2 & 2 & 2 & 2 & 3 & 3 & 3 & 1 & 1 & 1 \\
\hline 6 & 1 & 2 & 2 & 2 & 3 & 3 & 3 & 1 & 1 & 1 & 2 & 2 & 2 \\
\hline 7 & 1 & 3 & 3 & 3 & 1 & 1 & 1 & 3 & 3 & 3 & 2 & 2 & 2 \\
\hline 8 & 1 & 3 & 3 & 3 & 2 & 2 & 2 & 1 & 1 & 1 & 3 & 3 & 3 \\
\hline 9 & 1 & 3 & 3 & 3 & 3 & 3 & 3 & 2 & 2 & 2 & 1 & 1 & 1 \\
\hline 10 & 2 & 1 & 2 & 3 & 1 & 2 & 3 & 1 & 2 & 3 & 1 & 2 & 3 \\
\hline 11 & 2 & 1 & 2 & 3 & 2 & 3 & 1 & 2 & 3 & 1 & 2 & 3 & 1 \\
\hline
\end{tabular}


Tontchev N. The influence of elements on alloys properties

MEST Journal Vol. 1 No. 2 pp. 31 - 39

\begin{tabular}{|l|l|l|l|l|l|l|l|l|l|l|l|l|l|}
\hline Run & $\mathrm{X} 1$ & $\mathrm{X} 2$ & $\mathrm{X} 3$ & $\mathrm{X} 4$ & $\mathrm{X} 5$ & $\mathrm{X} 6$ & $\mathrm{X} 7$ & $\mathrm{X} 8$ & $\mathrm{X} 9$ & $\mathrm{X} 10$ & $\mathrm{X} 11$ & $\mathrm{X} 12$ & $\mathrm{X} 13$ \\
\hline 12 & 2 & 1 & 2 & 3 & 3 & 1 & 2 & 3 & 1 & 2 & 3 & 1 & 2 \\
\hline 13 & 2 & 2 & 3 & 1 & 1 & 2 & 3 & 2 & 3 & 1 & 3 & 1 & 2 \\
\hline 14 & 2 & 2 & 3 & 1 & 2 & 3 & 1 & 3 & 1 & 2 & 1 & 2 & 3 \\
\hline 15 & 2 & 2 & 3 & 1 & 3 & 1 & 2 & 1 & 2 & 3 & 2 & 3 & 1 \\
\hline 16 & 2 & 3 & 1 & 2 & 1 & 2 & 3 & 3 & 1 & 2 & 2 & 3 & 1 \\
\hline 17 & 2 & 3 & 1 & 2 & 2 & 3 & 1 & 1 & 2 & 3 & 3 & 1 & 2 \\
\hline 18 & 2 & 3 & 1 & 2 & 3 & 1 & 2 & 2 & 3 & 1 & 1 & 2 & 3 \\
\hline 19 & 3 & 1 & 3 & 2 & 1 & 3 & 2 & 1 & 3 & 2 & 1 & 3 & 2 \\
\hline 20 & 3 & 1 & 3 & 2 & 2 & 1 & 3 & 2 & 1 & 3 & 2 & 1 & 3 \\
\hline 21 & 3 & 1 & 3 & 2 & 3 & 2 & 1 & 3 & 2 & 1 & 3 & 2 & 1 \\
\hline 22 & 3 & 2 & 1 & 3 & 1 & 3 & 2 & 2 & 1 & 3 & 3 & 2 & 1 \\
\hline 23 & 3 & 2 & 1 & 3 & 2 & 1 & 3 & 3 & 2 & 1 & 1 & 3 & 2 \\
\hline 24 & 3 & 2 & 1 & 3 & 3 & 2 & 1 & 1 & 3 & 2 & 2 & 1 & 3 \\
\hline 25 & 3 & 3 & 2 & 1 & 1 & 3 & 2 & 3 & 2 & 1 & 2 & 1 & 3 \\
\hline 26 & 3 & 3 & 2 & 1 & 2 & 1 & 3 & 1 & 3 & 2 & 3 & 2 & 1 \\
\hline 27 & 3 & 3 & 2 & 1 & 3 & 2 & 1 & 2 & 1 & 3 & 1 & 3 & 2 \\
\hline
\end{tabular}

Thus, noise is expressed in the change of chemical composition. The calculation process is organized as follows:

A row of matrix I $(27,8)$ is taken (for example, row 1 - I (1,8)). In this row for each $x_{i}$ level "1" is assigned, i.e. noise will be taken out from each value $x_{i}$. Using the rule expresed in this way, noise is generally formed in the first row of matrix A (90.8), calculated by the mathematical model and the result forms $F(1,1)$ of matrix $F(27,90)$. The same rule is applies to the next rows of the matrix $A(90,8)$.

It is continued with the next row of matrix I $(27,8)$ performing the following sequence. Each row of matrix I $(27,8)$ forms a relevant row of matrix $F(27,90)$.

If we take the first column of matrix I $(27,8)$ relevant to $X_{1}$, it is seen that the first nine rows correspond to level "1" of noise, the second nine lines correspond to level "2" and the third nine rows correspond to level " 3 " of noise. This makes possible to use the values of the first nine rows of matrix $F(27,90)$ to calculate level "1", to use the second nine rows to calculate level of " 2 " and the third nine rows for calculation at level "3" for $X_{1}$. For other columns from 2 to 8 it is necessary to sort in ascending order. After sorting the column obtains the kind of the first column. If changes are made with sorting, they are reflected also in matrix $F(27,90)$. After sorting of the respective variable, calculations for different levels can be made.

Thus 810 different values of this function are obtained for each level of noise and this ensures reliable outcomes.

Table 4. Levels of noise factors for the research parameters

\begin{tabular}{|c|c|c|c|}
\hline Variable & $\begin{array}{c}\text { Element of } \\
\text { composition }\end{array}$ & \multicolumn{2}{|c|}{ Noise level } \\
\hline $\mathrm{X}_{1}$ & $\mathrm{Re}$ & $\mathrm{A}$ \\
\hline $\mathrm{X}_{2}$ & $\mathrm{Si}$ & 2 & 1 \\
\hline $\mathrm{X}_{3}$ & $\mathrm{Mn}$ & 1 & 1 \\
\hline $\mathrm{X}_{4}$ & $\mathrm{Ni}$ & 1 & 2 \\
\hline $\mathrm{X}_{5}$ & $\mathrm{~S} / \mathrm{P}$ & 2 & 2 \\
\hline $\mathrm{X}_{6}$ & $\mathrm{Cr}$ & 3 & 2 \\
\hline $\mathrm{X}_{7}$ & $\mathrm{Mo}$ & 3 & 1 \\
\hline $\mathrm{X}_{8}$ & $\mathrm{~V}$ & 1 & 1 \\
\hline
\end{tabular}




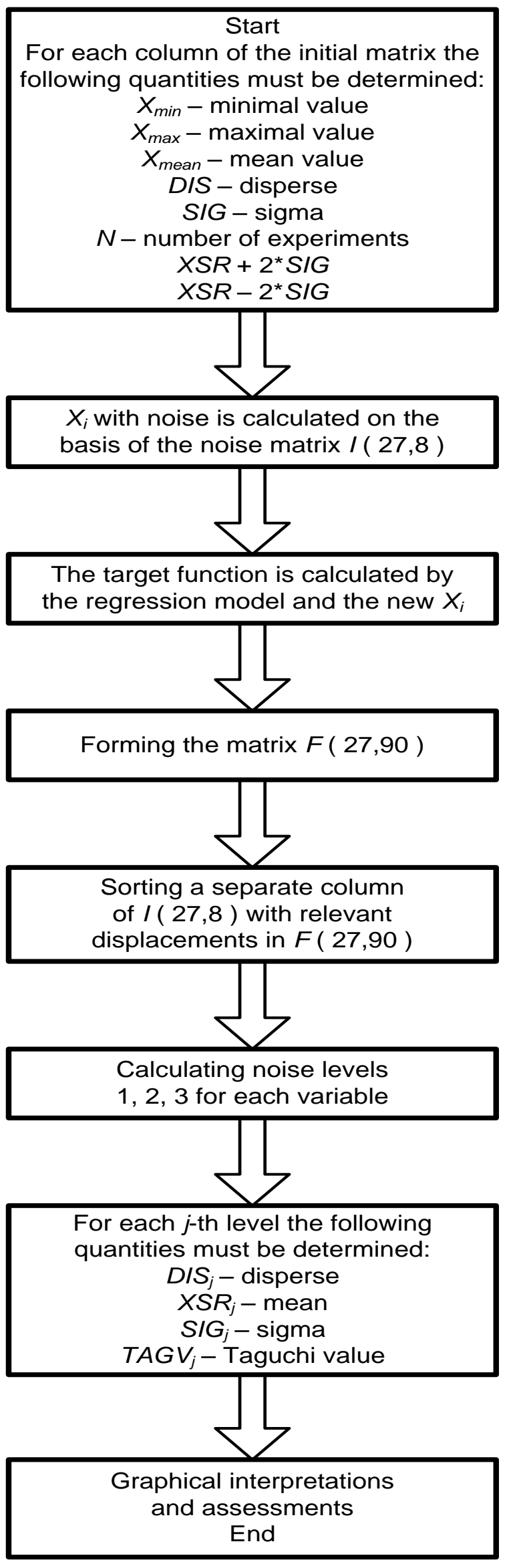

\section{Fig. 3 Computational algorithm}

In the numerical experiment noise was first determined with $k=100$. The analysis of the graphs below shows low sensitivity for both $R e$ and $\mathrm{A}$. For this reason, an experiment with $\mathrm{k}=70$ has been made as well. In these calculations, as shown in the attached graphs, the results are sharper for both target functions under examination. As explained above in this section, in compliance with Taguchi, the higher evaluation is taken as the optimal value. It defines the noise level and the direction of possible further search.

After the analysis of evaluations of the respective graphics for $\mathrm{Re}$ and $\mathrm{A}$, the generalization of the solution is shown in Table 4.

Calculations are performed according to the following algorithm.

\section{CONCLUSIONS}

The conclusion that can be made on yield strength $R e$ based on the results in the table is that silicon, sulfur and phosphorus do not significantly affect the ultimate outcome within the range of variation examined. Carbon, chromium and molybdenum influence significant on Re. These elements have to be modified in direction to increase their values. Manganese, nickel and vanadium should be modified in direction to decrease their values.

The results of the relative elongation $A$ are more interesting. The four variables, carbon, nickel, sulfur and chromium, should not be changed from their basic levels, and the other variables, silicon, manganese, molybdenum and vanadium, have to be modified in direction to reduce their values. The main conclusion of the applied methods towards the relative elongation is that none of the variables must be increased.

As a result of the procedure proposed it is possible to specify the quantity of alloying elements on ferrous alloys using Taguchi method.

It is expected to improve the respective properties of steel 35 HGSA regulated by GOST via increasing manganese. The last statement must be confirmed also by an actual experiment. 


\section{WORKS CITED}

Adem, C., Turgay, K., \& Gurcan, S. (2012). Application of Taguchi Metod for Surface Roughness and Roundness Error in Drilling of AISI 316 Stainless Steel. Journal of Mechanical Engineering, 58(3), 165-174.

Bajic, D., Jozic, S., \& Podrug, S. (2010). Design of Experiment's Application in the Optimization of Milling Process. Metalurgija, 49(2), 123-126.

Efimychev, Y., Mikhailov, S., Svyatkina, B., \& Prokhorov, I. (1976). Regresiony analysis of quality steels and alloys. Moskow: Metallurgy.

Gaitonde, V., Karmik, S., \& Davim, J. (2009). Multiperformance Optimization in Turning of FreeMachiningSteel Using Taguchi Method and Utility Concept. Journal of Materials Enginering \& Performance, 18(3), 231-237.

Kachar, R. (1985). Off line quality control parameters desing and Taguchi method. Journal of Quality Technology(17), 176-209.

Kachar, R. (1986). Robust design: Cost - effective method for improving in manufacturing processes. AT\&T Technical journal, 65(2), 39-50.

Kochure, P., \& Nandurkar, K. (2012). Application of Taguchi Metodology in Selection of Process Parameters for Induction Hardening Of EN8 D Steel. International Journal of Modern Enginering Research (IJMER), Vol.2 (2012), 5, 2(5), 3736 - 3742.

Naveen, B., Maheshwari, S., Sharma, C., \& Anil, K. (2008). Perfomance Evaluation of Powder Metallurgy Electrode in Electrical Discharge Machining of AISI D2 Steel Using Taguchi Method. Enginering and Technology(14), 576-580.

Oji, J., Pamtoks, S., Idusuyi, N., \& Aliu, T. (2012). Statistical model for predict the ultimade tensile strength of aluminium alloy sand castings under different process parameters. New York Science Journal, 10(5), $20-25$.

Ramesh, C., \& Suresh, K. R. (2012). Mathematical and Neural Network Models for Prediction of Wear of Mild Steel Coated with Inconel 718 - A, Comparative Study. International Journal of Scientific and Research Publications, 2(7). Retrieved from www.ijsrp.org

Rozhkov, I., Vlasov, S., \& Mulk, G. (1990). Mathematical models for the choice of optimal technology and quality control of steel. Moskow: Metallurgy.

Vuchkov, I., \& Stoyanov, S. (1980). Mathematical modeling and optimization of technological objects. Sofia: Technique.

\section{ACKNOWLEDGEMENTS}

This research is realized with the financial support of the National Fund "Scientific Research" of Bulgaria about Contract DDVU 02-11.

Received for publication:

07.02 .2013

Revision received:

25.03.2013

Accepted for publication:

12.04.2013 


\section{How to cite this article?}

Style - APA Sixth Edition:

Tontchev, N., \& Kalev, Y. (2013, 07 15). Determining influence of alloying elements on properties of alloys by robust experiment. (Č. Zoran, Ed.) MEST Journal, 1(2), 31-39. doi:10.12709/mest.01.01.02.03

Style - Chicago Fifteenth Edition:

Tontchev, Nikolay and Yordan Kalev. "Determining influence of alloying elements on properties of alloys by robust experiment." Edited by Čekerevac Zoran. MEST Journal (MESTE) 1, no. 2 (07 2013): 31-39.

Style - GOST Name Sort:

Tontchev Nikolay and Kalev Yordan Determining influence of alloying elements on properties of alloys by robust experiment [Journal] = The influence of elements on alloys properties // MEST Journal / ed. Zoran

Čekerevac. - Belgrade : MESTE, 07 15, 2013. - 2 : Vol. 1. - pp. 31-39. - ISSN 2334-7058 (Online); ISSN 23347171.

Style - Harvard Anglia:

Tontchev, N. \& Kalev, Y., 2013. Determining influence of alloying elements on properties of alloys by robust experiment. MEST Journal, 15 07, 1(2), pp. 31-39.

Style - ISO 690 Numerical Reference:

Determining influence of alloying elements on properties of alloys by robust experiment. Tontchev, Nikolay and Kalev, Yordan. [ed.] Čekerevac Zoran. 2, Belgrade : MESTE, 07 15, 2013, MEST Journal, Vol. 1, pp. 31-39. ISSN 2334-7058 (Online); ISSN 2334-7171. 